\title{
SASARAN STRATEGIS PERUSAHAAN PERKEBUNAN KELAPA SAWIT TELADAN PRIMA GROUP
}

\section{STRATEGIC OBJECTIVES OF PLANTATION COMPANY PALM OIL TELADAN PRIMA GROUP}

\section{Sali Subakti *), Rizal Syarief **), dan Iyung Pahan***)}

*) Teladan Prima Group

Jl. T.B. Simatupang No. 41, Beltway Office Park, Gedung B Lantai 7, Jakarta 12560

**)Departemen Ilmu dan Teknologi Pangan, Fakultas Teknologi Pertanian, Institut Pertanian Bogor

PO Box 220, Kampus IPB Dramaga Bogor 16002

***) DMI Consulting Firm

Jakarta Selatan 12930

\begin{abstract}
Teladan Prima Group (TPG) as one of the palm oil plantations company have a strategic objectives in perspective of financial, customer, internal business processes, and learning and growth with the implementation of the Balanced Scorecard (BSC). The efforts to improve of high productivity of all resources that owned, are effectiveness managed with cost efficiency is the ultimate goal of company performance measurement. The problems occurred, management is confronted on the issues of the achievement of company performance targets that are not optimal and the strategic objectives of the company have not been cascaded down in a balanced way. The purpose of this research is to analyze of the strategic objectives and the implementation of BSC by using the technique of analysis of fourteen strategic objectives of the company in the four BSC perspectives with the integration of analytic network process (ANP). Results from the processing of primary data obtained through in-depth interviews and pairwise comparison of 7 respondents on the company executive level shows the results: financial perspective has the biggest weighting $42.21 \%$, internal business process perspective $27.45 \%$, customer perspective $16.29 \%$ growth and learning perspective $14.04 \%$ with consistency ratio (CR) $2.14 \%$ which means the respondent opinion is acceptable and consistent.
\end{abstract}

Keywords: strategic objectives, balanced scorecard, ANP, oil palm

\begin{abstract}
Abstrak: Teladan Prima Group (TPG) sebagai salah satu perusahaan perkebunan kelapa sawit memiliki sasaran strategi dalam perspektif kinerja keuangan, pelanggan, proses bisnis internal dan pembelajaran dan pertumbuhan dengan penerapan Balanced Scorecard (BSC). Upaya peningkatan produktivitas sumberdaya yang dimiliki, dengan efektivitas pengelolaan dan efisiensi biaya merupakan tujuan akhir dari pengukuran kinerja perusahaan. Permasalahan yang terjadi, manajemen dihadapkan pada isu pencapaian target kinerja perusahaan yang belum optimum dan sasaran strategis perusahaan belum diturunkan secara seimbang. Tujuan penelitian ini adalah untuk menganalisis sasaran strategis dan implementasi BSC dengan menggunakan teknik analisis terhadap 14 sasaran strategis perusahaan di dalam empat perspektif BSC dengan integrasi proses jejaring kerja analitik (ANP). Dari hasil pengolahan data primer yang diperoleh melalui wawancara secara mendalam dan kuesioner perbandingan berpasangan terhadap 7 responden level eksekutif perusahaan menunjukkan hasil: perspektif kinerja keuangan memiliki bobot terbesar $42,21 \%$, kinerja proses bisnis internal $27,45 \%$, kinerja pelanggan $16,29 \%$, dan kinerja pertumbuhan dan pembelajaran SDM 14,04\% dengan tingkat rasio inkonsistensi (CR) sebesar $2,14 \%$ yang berarti konsistensinya dapat diterima dan konsisten.
\end{abstract}

Kata kunci: sasaran strategis, balanced scorecard, ANP, kelapa sawit

1 Alamat Korespondensi:

Email:sali.subakti@teladanprima.com 


\section{PENDAHULUAN}

Kelapa Sawit (Elaeis guineensis) sebagai salah satu tanaman komoditas dengan produk utama minyak sawit/crude palm oil (CPO) memberikan efek multifungsi dan manfaat ganda bagi perekonomian indonesia dan dunia secara keseluruhan (GAPKI, 2014). Berbagai fungsi dan manfaat tersebut meliputi aspek ekonomi (profit), sosial (people), dan ekologi (planet) yang selaras dengan konsep triple bottom line, yaitu suatu konsep berkelanjutan dari tujuan pembangunan dan bisnis perusahaan masa depan (Elkington, 1997).

Manfaat dari aspek ekonomi, industri minyak sawit dan produk turunannya saat ini telah berkembang menjadi sumber penyedia produk bahan pangan (oleofood), bahan baku minyak dan energi (biofuel) serta industri kimia dan farmasi (oleochemical) yang paling efisien dan dibutuhkan baik bagi Indonesia maupun masyarakat global. Manfaat dari aspek sosial, industri sawit berperan dalam kontribusinya menciptakan kesempatan kerja, pembangunan daerah terpencil dan kawasan perdesaan serta pengentasan kemiskinan di perdesaan.

Dari berbagai studi empiris (Susila, 2004; World Growth, 2011; PASPI, 2016) mengungkapkan bahwa perkebunan Kelapa Sawit di Indonesia merupakan bagian penting dari pembangunan kawasan terpencil maupun pengurangan kemiskinan perdesaan. Selain itu perkebunan kelapa sawit memiliki fungsi ekologis dan jasa lingkungan yang berfungsi mirip seperti hutan (Fairhurst dan Hardter, 2004; PASPI, 2016). Perkebunan kelapa sawit merupakan bagian penting dari siklus karbondioksida, siklus oksigen dan siklus air. Menurut Henson (1999), PPKS $(2004,2005)$ dalam PASPI (2016), kemampuan perkebunan kelapa sawit menyerap $\mathrm{CO}_{2}$ dan menghasilkan $\mathrm{O}_{2}$ lebih tinggi dari kemampuan hutan primer. Bila melihat planet bumi sebagai satu kesatuan ekosistem, fungsi ekologis perkebunan kelapa sawit tersebut akan dinikmati secara gratis oleh masyarakat dunia.

Sebaliknya dari aspek eksternal, perkembangan pembangunan industri perkebunan kelapa sawit menghadapi tantangan berbagai isu permasalahan global dan domestik dari berbagai bidang meliputi: ekonomi, sosial, lingkungan, regulasi/kebijakan, teknologi, pengembangan produk dan tatakelola manajemen sumberdaya yang sangat kompleks. Oleh karena itu, setiap perusahaan dituntut untuk selalu dapat beradaptasi terhadap dinamika perubahan yang berkembang sejalan dengan peningkatan perbaikan kinerja secara berkelanjutan (continuous improvement) untuk menciptakan nilai tambah dan daya saing serta keunggulan melalui peningkatan produktivitas seluruh sumberdaya dan biaya yang efisien.

MenurutResse(2010), semakin meningkatnya persaingan usaha dan permintaan pasar mengharuskan perusahaan berusaha mengelola setiap sumberdaya yang ada dengan lebih baik. Keunggulan bersaing, pangsa pasar, dan keuntungan senantiasa menjadi sasaran persaingan dan perubahan (Stynes, 2011). Untuk tetap bertahan hidup dan tumbuh ditengah kompetisi dan persaingan global, setiap perusahaan dituntut mampu beradaptasi terhadap dinamika perubahan lingkungan yang sangat cepat dan semakin kompleks melalui eksekusi sasaran strategi yang fokus dan jelas sesuai visi dan misi perusahaan (Pahan, 2004). Visi dan misi perusahaan yang jelas dan fokus akan sangat membantu saat mengaplikasikan program kerjanya. Berdasarkan hal tersebut, manajemen menyusun rumusan strategi bisnis yang diterjemahkan ke dalam program serta sasaran strategis yang dibuat secara aplikatif (bisa dikerjakan) dan fleksibel terhadap situasi dan kondisi yang dihadapi agar perusahan dapat mencapai tujuannya (Mulyadi, 2007).

Dalam peningkatan produktivitas dan pertumbuhan dalam lingkup organisasi/perusahaan, para pimpinan juga dihadapkan dengan permasalahan kesenjangan (gap) produktivitas, kultur teknis, pengelolaan tenaga kerja dan optimalisasi aset/sumber daya serta faktor lainnya yang sangat tinggi dan memengaruhi proses penciptaan hasil dan menjaga keseimbangan nilai pemilik dan pemangku kepentingan lain. TPG sebagai salah satu perusahaan perkebunan kelapa sawit sedang berupaya untuk meningkatkan produktivitas dan pertumbuhan usahanya. Dalam operasionalnya, perusahaan dihadapkan dengan permasalahan kesenjangan/gap rendahnya produktivitas yang berpengaruh terhadap aspek pencapaian kinerja keuangan, pelanggan, proses bisnis internal dan pertumbuhan dan pembelajaran. Hal tersebut memengaruhi proses keseimbangan dalam penciptaan hasil dan nilai bagi seluruh pemangku kepentingan. Oleh karena itu, agar tujuan usaha meraih produktivitas sumber daya yang tinggi dan dikelola secara efektif dan efisien dapat diraih maka dalam proses pengukuran kinerja dan hasilnya diperlukan umpan balik dan peningkatan perbaikan secara terus menerus oleh manajemen dan seluruh karyawan secara konsisten. 
Sesuai dengan permasalahan tersebut, proses manajemen strategi formal melalui analisis sasaran strategis perusahaan dalam kerangka implementasi balanced scorecard (BSC) di TPG diperlukan untuk menjawab apakah sasaran strategis masih relevan dengan kondisi terkini dan ke depan serta apakah proses cascaded down antar lintas fungsi sudah seimbang. Oleh karena itu, penelitian ini mencoba melakukan analisis sasaran strategis perusahaan perkebunan kelapa sawit TPG dengan integrasi proses jejaring kerja analitik (ANP) dan BSC. Tujuan penelitian ini adalah menentukan bobot sasaran strategis persepektif BSC yang seimbang dengan melakukan penyusunan prioritas berbasis perbandingan berpasangan dari opini seluruh eksekutif TPG.

\section{METODE PENELITIAN}

Penelitian dilaksanakan pada perusahaan perkebunan kelapa sawit TPG. Dibatasi dalam lingkup kajian analisis 14 sasaran strategis sesuai peta strategi perspektif BSC perusahaan (Tabel 1). Di samping itu, survei prinsip-prinsip strategy focused organization untuk mengetahui efektivitas penerapan BSC di TPG. Data sekunder diperoleh dari dokumen internal perusahaan termasuk referensi luar perusahaan berupa studi literatur sesuai bidang objek penelitian. Data primer diperoleh dari hasil survei dan wawancara mendalam (indepth interview) terhadap responden terpilih.
Pengumpulan data dilakukan melalui studi literatur sesuai bidang kajian penelitian, wawancara/indepth interview, dan kuesioner terdiri dari kuesioner 1 dan kuesioner 2. Kuesioner 1 merupakan survei perbandingan berpasangan (pairwise comparison) sasaran strategis dalam kerangka BSC TPG dengan penedakatan metode Analytic Network Process (ANP). Responden ahli terpilih dalam survei ini terdiri dari 7 responden level top manajemen/executives (decision maker) (Tabel 2). Selanjutnya, kuesioner 2 adalah survei implementasi sistem manajemen kinerja BSC TPG pendekatan prinsip-prinsip Strategy Focused Organization (SFO) Kaplan dan Norton (kuesioner disajikan pada bagian lampiran). Survei bertujuan mengetahui level efektivitas implementasi BSC dan memastikan apakah manajemen kinerja sudah berjalan dan searah visi dan misi TPG. Responden dalam survei ini berjumlah 147 orang mulai dari level eksekutif (3), manager (28) hingga staf/asisten (109) di kantor pusat/ perwakilan hingga unit usaha.

Penelitian analisis sasaran strategis dan implementasi BSC dilakukan dengan analisis deskriptif. Untuk menentukan pembobotan ideal masing-masing sasaran strategis (strategic objectives) sesuai peta strategi, dilaksanakan dengan pendekatan proses jejaring kerja analitik/ANP. Proses analisis terhadap proritas/ bobot sasaran strategis BSC TPG dibagi dalam tiga tahap yakni: dekomposi model, penyusunan kuesioner perbandingan berpasangan (pairwise comparison) dan proses analisis serta pengolahan data (Gambar 1).

Tabel 1. Perspektif dan Sasaran Strategis BSC TPG

\begin{tabular}{ll}
\hline \multicolumn{1}{c}{ Kriteria (Cluster) } & \multicolumn{1}{c}{ Subkriteria/Simpul (Node) } \\
\hline Perspektif BSC & \multicolumn{1}{c}{ Sasaran strategis } \\
\hline Keuangan & Optimalisasi biaya \\
& Menjaga pertumbuhan berkelanjutan \\
Pelanggan & Meningkatkan citra perusahaan \\
& Meningkatkan loyalitas pelanggan \\
Proses internal & Penambahan luas tanaman \\
& Meningkatkan produktivitas \& kualitas \\
& Optimalisasi penjualan \& kualitas delivery \\
& Inisiasi produk sampingan \\
& Peningkatan mutu HSE \\
& Pengendalian biaya \\
& Meningkatkan kehandalan SOP \\
& Meningkatkan kompetensi SDM \\
& Mengembangkan SIM \\
\hline
\end{tabular}


Tabel 2. Profil responden penelitian

\begin{tabular}{llll}
\hline \multicolumn{1}{c}{ Nama responden } & \multicolumn{1}{c}{ Jabatan } & \multicolumn{1}{c}{ Fungsi } & \multicolumn{1}{c}{ Pengalaman kerja } \\
\hline Responden 1 & Chief Executive Officer & Management & 12 Tahun \\
Responden 2 & Plantation Div. Head & Line Function & 28 Tahun \\
Responden 3 & Engineering Div. Head & Line Function & 28 Tahun \\
Responden 4 & Business Support Div. Head & Support Function & 28 Tahun \\
Responden 5 & Finance Div. Head & Support Function & 25 Tahun \\
Responden 6 & Marketing Dept. Head & Support Function & 12 Tahun \\
Responden 7 & HRM Dept. Head & Support Function & 22 Tahun \\
\hline
\end{tabular}

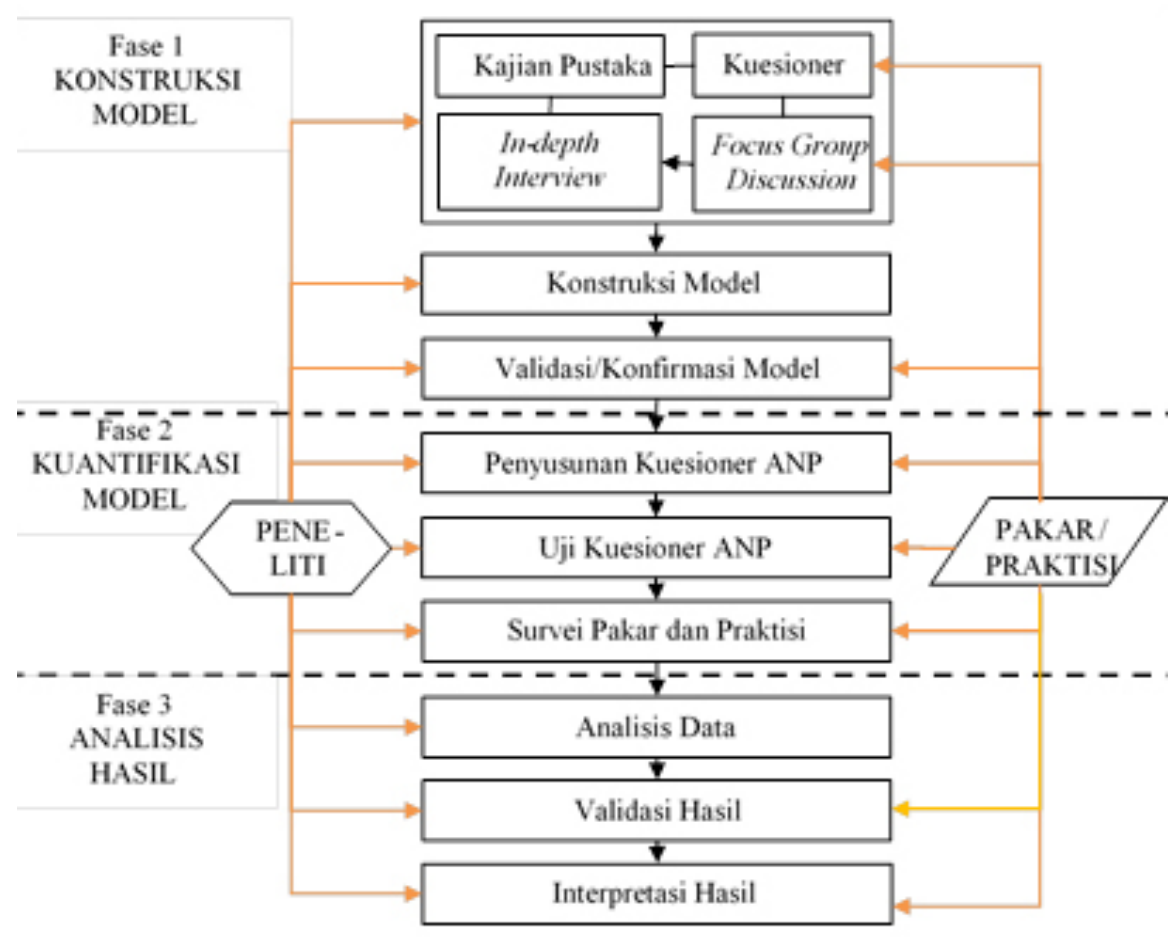

Gambar 1. Tahapan penelitian dengan kerangka ANP (Pahan et al. 2012)

\section{HASIL}

Hasil pengumpulan dan pengolahan data maka perlu dianalisis lebih lanjut untuk mengetahui dan memahami kondisi TPG mengenai prioritas sasaran strategis yang digunakan untuk mencapai tujuan sesuai visinya. Selanjutnya melakukan evaluasi terhadap implementasi BSC TPG melalui analisis prinsip-prinsip SFO.

\section{Analisis Sasaran Strategis}

Hasil pengolahan data ANP melalui analisis sasaran strategis BSC TPG, secara berurut diperoleh nilai perspektif keuangan memiliki bobot terbesar $42,21 \%$, proses bisnis internal $27,45 \%$, pelanggan $16,29 \%$ dan per-spektif pertumbuhan dan pembelajaran 14,04\%. hasil tersebut selengkapnya pada Gambar 2.
Sekilas hal tersebut menunjukkan bahwa prioritas manajemen dalam mewujudkan tujuan dan visi perusahaan adalah fokus pada aspek kinerja keu-angan. Hal itu belum dapat diartikan bahwa secara keseluruhan manajemen TPG lebih menitikberatkan (dominan) pada usaha-usaha pencapaian kinerja perspektif keuangan, karena juga harus melihat dari masing-masing sasaran strategis perspektif lainnya.

Tingkat Consistency Ratio (CR) menunjukkan nilai rata-rata sebesar $2,14 \%$ yang berarti hasil pengujian terhadap konsistensi jawaban responden sudah valid (atau dapat diterima) karena berada dibawah standar $\mathrm{CR}=<10 \%$ (Tabel 3). Sebaliknya nilai rater agreement atau tingkat kesesuaian/kesepakatan (persetujuan) diantara responden ahli menunjukkan perbedaan signifikan. Hal ini sesuai hasil pengujian Kendall's coefficient of concordance (W) menunjukkan rata-rata nilai sebesar 0,47988 (atau 47,99\%) yang berarti belum 
memenuhi syarat konsensus kesepakatan $>50 \%$ pada level rater agreement tertinggi 1 atau 100\% (sempurna). Hal ini mengidentifikasikan tingkat kesepakatan yang rendah diantara fungsi manajemen baik line function dan terlebih support function TPG (ego divisional).

Selanjutnya, harus diingat tujuan dari adanya bobot atau prioritas mas-ing-masing sasaran strategis pada perspektif BSC adalah untuk membanding-kan tingkat/derajat kepentingan diantara sasaran strategis sesuai pendapat ahli (decision maker) yang akan diimplementasikan dalam bentuk kontrak kinerja yang sinergi antar masing-masing fungsi dalam mencapai tujuan perusahaan (corporate). Secara terperinci nilai keterkaitan masing-masing sasaran strategis sesuai peta strategi BSC TPG dapat disajikan pada Tabel 4.

Merujuk nilai limiting supermatrix sasaran strategis sesuai Tabel 4, dapat disimpulkan bahwa untuk mencapai visi dan misinya, manajemen TPG harus lebih menitikberatkan pada upaya pencapaian kinerja perspektif keuangan dengan sasaran strategis optimalisasi biaya dengan nilai rata-rata $16,22 \%$, maksimalisasi penjualan $13,16 \%$, dan menjaga pertumbuhan bisnis yang berkelanjutan $12.83 \%$. Hal tersebut secara khusus lebih didominasi oleh opini dan pendapat management dan fungsi pendukung (support function).

\section{Bobot Sasaran Strategis by Function}

Hasil analisis dan pengambilan keputusan dalam rangka untuk mengetahui prioritas sasaran strategis BSC di TPG dikelompokkan dalam tiga bagian responden (decision maker), yaitu kelompok fungsi lini/operasional (line function), kelompok pendukung (support function) serta manajemen. Bila melihat hasil analisis berdasarkan kelompok function tersebut, secara keseluruhan pengambilan keputusan baik oleh manajemen secara global lebih menitikberatkan pada sasaran strategis secara berurut; optimalisasi biaya $(0,1622)$, maksimalisasi penjualan $(0,1316)$, menjaga pertumbuhan $(0,1283)$, loyalitas pelanggan $(0,0939)$ dan kompetensi $\operatorname{SDM}(0,0819)$ sebagai top 5 dari prioritas strategi kinerja perusahaan.

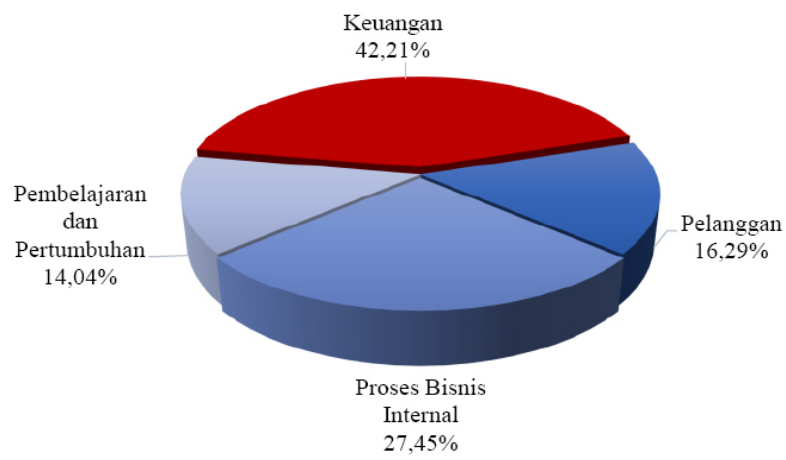

Gambar 2. Persentase sasaran strategis TPG

Tabel 3. Rekapitulasi hasil analisis sasaran strategis TPG

\begin{tabular}{|c|c|c|c|c|c|c|}
\hline \multirow{2}{*}{ Name } & \multicolumn{4}{|c|}{ Limiting Supermatrix by } & \multirow{2}{*}{$\begin{array}{c}\text { Persentase } \\
\text { existing }\end{array}$} & \multirow{2}{*}{ Selisih } \\
\hline & Line function & Support function & Management & Total & & \\
\hline \multicolumn{7}{|l|}{ Balanced Scorecard } \\
\hline Keuangan & $36,83 \%$ & $43,58 \%$ & $46,22 \%$ & $42,21 \%$ & $30 \%$ & $12 \%$ \\
\hline Customer & $27,29 \%$ & $9,27 \%$ & $12,32 \%$ & $16,29 \%$ & $10 \%$ & $6 \%$ \\
\hline Internal Business Process & $24,14 \%$ & $31,15 \%$ & $27,07 \%$ & $27,45 \%$ & $40 \%$ & $-13 \%$ \\
\hline Learning \& Growth & $11,73 \%$ & $16,00 \%$ & $14,39 \%$ & $14,04 \%$ & $20 \%$ & $-6 \%$ \\
\hline Total & $100,00 \%$ & $100,00 \%$ & $100,00 \%$ & $100,00 \%$ & $100 \%$ & $0 \%$ \\
\hline \multicolumn{7}{|l|}{ Notes } \\
\hline No of respondent (n) & 2 & 4 & 1 & 7 & & \\
\hline CR (Consistency Ratio) & $1,96 \%$ & $2,12 \%$ & $2,57 \%$ & $2,14 \%$ & & \\
\hline W (Kendall's Concordance) & 0,85714 & 0,45055 & 1,00000 & 0,47988 & & \\
\hline
\end{tabular}

Note: a) standar consistency ratio $(\mathrm{CR}=<10 \%)$, semakin kecil semakin valid (lebih baik); b) standar rater agreement dengan Kendall's coefficient of concordance $(\mathrm{W} ; 0<\mathrm{W}<1)$. W=1 menunjukkan kesesuaian yang sempurna. 


\section{Bobot Lokal Sasaran Strategis}

Bobot lokal menunjukkan prioritas suatu sasaran strategis dengan sasaran strategis lainnya yang masih berada dalam perspektif yang sama (Gambar 3). Bila melihat bobot lokal dari nilai prioritas sasaran strategis di masing-masing perspektif dapat disampaikan bobot tertinggi pada perspektif keuangan adalah optimalisasi biaya $(16,22 \%)$, perspektif pelanggan adalah loyalitas pelanggan $(9,39 \%)$, perspektif proses internal adalah pengendalian biaya $(6,11 \%)$, dan perspektif pembelajaran dan pertumbuhan adalah kompetensi $\operatorname{SDM}(8,19 \%)$.

Tabel 4. Perbandingan prioritas sasaran strategis limiting supermatrix

\begin{tabular}{|c|c|c|c|c|c|c|c|}
\hline \multirow{2}{*}{ Perspektif } & \multirow{2}{*}{ Sasaran strategis } & \multicolumn{3}{|c|}{ Limiting supermatrix } & \multirow{2}{*}{$\begin{array}{l}\text { Bobot } \\
\text { global }\end{array}$} & \multirow{2}{*}{ Ranking } & \multirow{2}{*}{$\begin{array}{c}\text { Bobot } \\
\text { perspektif }\end{array}$} \\
\hline & & Line & Support & Management & & & \\
\hline \multirow[t]{3}{*}{ Keuangan } & Maksimalisasi penjualan & 0,1277 & 0,0911 & 0,1761 & 0,1316 & 2 & 0,4221 \\
\hline & Optimalisasi biaya & 0,1053 & 0,2126 & 0,1688 & 0,1622 & 1 & \\
\hline & Menjaga pertumbuhan berkelanjut & 0,1353 & 0,1322 & 0,1173 & 0,1283 & 3 & \\
\hline \multirow[t]{2}{*}{ Pelanggan } & Citra perusahaan & 0,1210 & 0,0369 & 0,0492 & 0,0690 & 6 & 0,1629 \\
\hline & Loyalitas pelanggan & 0,1519 & 0,0558 & 0,0740 & 0,0939 & 4 & \\
\hline \multirow{7}{*}{$\begin{array}{l}\text { Proses } \\
\text { Internal }\end{array}$} & Penambahan luas tanaman & 0,0314 & 0,0250 & 0,0188 & 0,0250 & 14 & 0,2745 \\
\hline & Produktivitas dan kualitas produk & 0,0482 & 0,0587 & 0,0605 & 0,0558 & 9 & \\
\hline & Optimalisasi penjualan dan kualitas & 0,0387 & 0,0402 & 0,0607 & 0,0465 & 10 & \\
\hline & Inisiasi produk sampingan & 0,0434 & 0,0182 & 0,0177 & 0,0264 & 12 & \\
\hline & Peningkatan mutu HSE & 0,0247 & 0,0336 & 0,0208 & 0,0264 & 13 & \\
\hline & Pengendalian biaya & 0,0340 & 0,0777 & 0,0716 & 0,0611 & 7 & \\
\hline & Meningkatkan kehandalan SOP & 0,0211 & 0,0581 & 0,0207 & 0,0333 & 11 & \\
\hline \multirow{2}{*}{$\begin{array}{l}\text { Pembelajaran } \\
\text { dan } \\
\text { Pertumbuhan }\end{array}$} & Kompetensi SDM & 0,0754 & 0,0747 & 0,0956 & 0,0819 & 5 & 0,1404 \\
\hline & Pengembangan SIM & 0,0419 & 0,0853 & 0,0483 & 0,0585 & 8 & \\
\hline
\end{tabular}

\section{Keuangan}

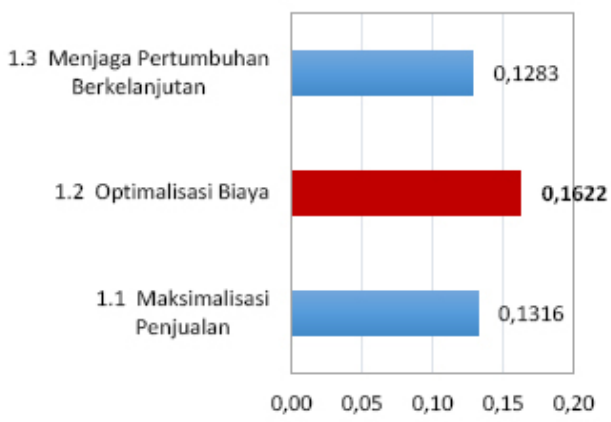

Pelanggan

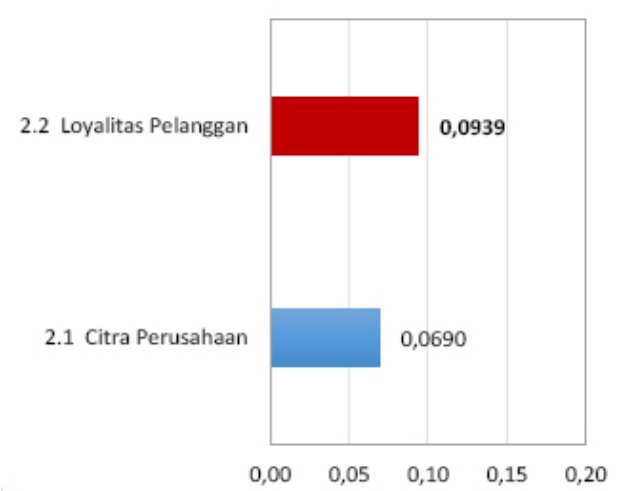

\section{Internal Proses}

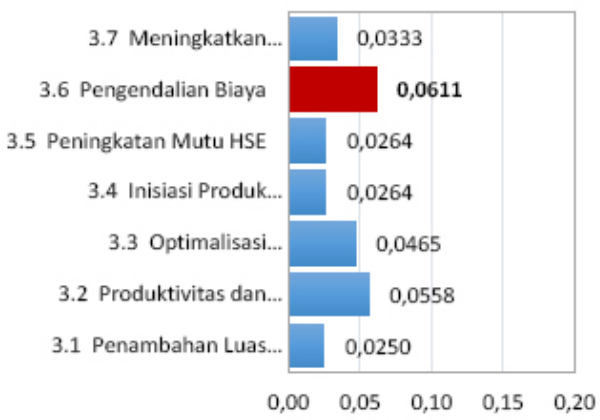

Pembelajaran

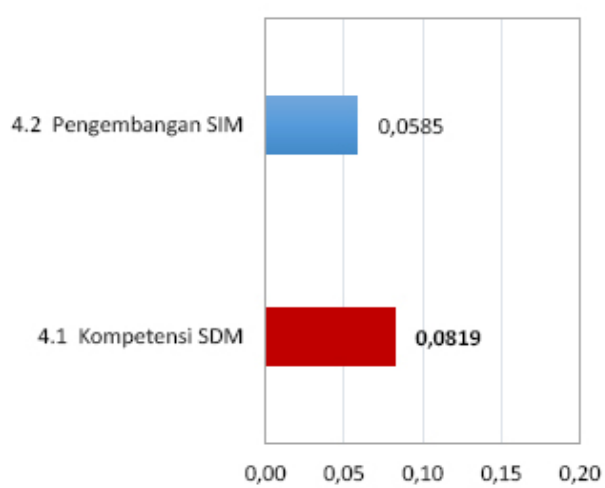

Gambar 3. Bobot lokal sasaran strategis kelompok perspektif 


\section{Perbandingan Bobot Perspektif Penelitian vs Perusahaan}

Perbedaaan bobot antara hasil penelitian (akademis) dengan bobot existing perusahaan dimana selisih pada perspektif keuangan $(12,21)$, proses bisnis internal $(-12,29)$, pelanggan $(6,29)$ dan perspektif pertumbuhan dan pembelajaran $(-5,96)$ (Gambar 4). Hal ini mengindikasi-kan perlunya perubahan bobot yang ada oleh manajemen TPG dengan pem-bobotan hasil penelitian.

\section{Implikasi Manajerial}

Beberapa hal yang dapat dijadikan arahan kebijakan bagi manajemen TPG adalah implikasi teoritis dan implikasi praktis. Implikasi teoritis hasil penelitian ini merupakan bukti empiris terhadap teori yang mendasari hubungan antara variabel dalam kesepakatan pilihan/ prioritas strategi, tingkat konsistensi manajemen yang tinggi dan koreksi terhadap kesenjangan pendapat agar lebih searah dan fokus terhadap tujuan jangka pendek, menengah maupun jangka panjang perusahaan. Di samping itu, implikasi praktis penelitian ini dapat dijadikan acuan oleh manajemen TPG untuk melakukan peningkatan perbaikan secaraterus menerus (continuous improvement) dalam konteks tujuan akhir pengukuran kinerja perusahaan yakni meraih produktivitas sumber daya yang tinggi, dengan mewujudkan pengelolaan hasil secara efektif dan efisien.

\section{KESIMPULAN DAN SARAN}

\section{Kesimpulan}

Sesuai dengan perumusan masalah dan tujuan penelitian yang ditindaklanjuti dengan pengolahan data dan analisis hasil penelitian maka dapat diambil kesimpulan bahwa manajemen TPG untuk mencapai visi dan misinya, harus lebih menitikberatkan upaya pencapaian kinerja perspektif keuangan sebesar 42,21\% dengan urutan prioritas sasaran strategis: (a) optimalisasi biaya $16.22 \%$, (b) maksimalisasi penjualan $13,16 \%$, dan (c) menjaga pertumbuhan berkelanjutan $12,83 \%$. Pembobotan perspektif keuangan ini harus diimbangi dengan perspektif proses internal $27,45 \%$, perspektif pelanggan $16,29 \%$, serta perspektif pemebelajaran dan petumbuhan SDM 14,04\%. Pembobotan terhadap empat belas sasaran strategis BSC TPG menunjukkan adanya kekurangsepahaman pendapat antar-eksekutif terhadap sasaran strategis apa yang menjadi prioritas paling penting dalam upaya pencapaian visi karena adanya ego sektoral Divisi. Hal ini ditunjukkan oleh pengujian nilai koefisien Kendall (W) sebesar 0,47988 (47,99\%) yang belum memenuhi syarat konsensus kesepakatan $>50 \%$. Perbedaaan prioritas sasaran strategis dan perspektifsesuaibobot penelitian akademis dibanding bobot existing perusahaan dengan selisih pada perspektif keuangan (12\%), proses bisnis internal $(-13 \%)$, pelanggan $(6 \%)$ dan perspektif pertumbuhan dan pembelajaran (-6\%). Hal ini dapat menjadi bahan pertimbangan bagi manajemen untuk melakukan koreksi dan review terhadap pembobotan sasaran strategis perusahaan untuk dijadikan pedoman dalam menurunkan (cascaded down) sasaran perusahaan ke level Divisi/Departemen dan level individual.
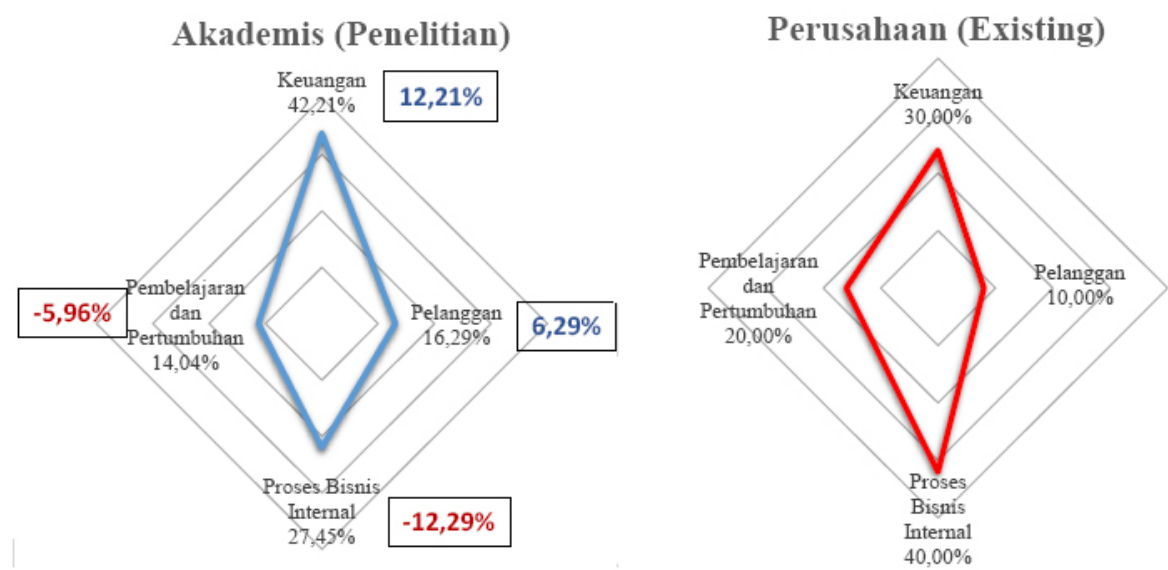

Gambar 4. Perbandingan bobot perspektif BSC versi penelitian vs perusahaan 


\section{Saran}

Penelitian ini menjadi sebuah awalan untuk pengembangan penelitian lanjutan agar analisis dapat dilakukan dengan lebih tepat. Untuk lebih mendapatkan keyakinan akan pemecahan masalah dalam penelitian ini, dapat dilakukan penelitian lanjutan dari penurunan (cascaded down) dan penyelarasan (alignment) peta strategi dan sasaran strategis perusahaan ke tingkat divisi/departemen hingga level individual yang lebih rendah secara menyeluruh melalui pendekatan kontrak kinerja dengan mengacu pada pembobotan sasaran strategis dari hasil penelitian ini.

\section{DAFTAR PUSTAKA}

Elkington J. 1997. Cannibals with Forks: The Triple Bottom Line of Twenty-First Century Business. London: Capstone Publishing Ltd, Oxford.

Fairhurst T, Hardter R. 2004. Oil Palm: Management for Large and Sustainable Yields. Oxford: Oxford Graphic Printers, Pte Ltd.
[GAPKI] Gabungan Pengusaha Kelapa Sawit Indonesia. 2014. Industri Minyak Sawit Indonesia Menuju 100 Tahun NKRI. Bogor: GAPKI.

Mulyadi. 2007. Sistem Terpadu Pengelolaan Kinerja Personel Berbasis Balanced Scorecard. Yogyakarta: Sekolah Tinggi Ilmu Manajemen YKPN.

[PASPI] Palm Oil Agribusiness Strategic Policy Institute. 2016. Mitos dan Fakta Industri Minyak Sawit Indonesia dalam Isu Sosial, Ekonomi dan Lingkungan Global. Bogor: PASPI.

Pahan I. 2004. Kiat Keberhasilan Bisnis Sepanjang Masa. Bagaimana Hu-man Capital Berperan Dalam Meningkatkan Nilai Para Pemegang Saham. Jakarta: Gramedia.

Pahan I, Gumbira-Sa'id E, Tambunan M, Suroso AI. 2012. Development of Palm Oil Industrial Cluster in Indonesia: An Analytic Network Process Study. Saarbrücken: Lambert Academic Publishing.

Stynes DJ. 2011. Economic Benefits to Local Communities from National Park Visitation and Payroll. Colorado: Michigan State University.

World Growth. 2011. The economic benefit of palm oil to Indonesia. Melbourne: World Growth Institute. 